Ensayo Original / Original Essay

\title{
El Proceso de Enseñar y Aprender: Indagación desde el Contexto Educativo
}

\author{
Autor: Ciro Hernández Valderrama \\ Instituto Universitario de Tecnología Puerto Cabello, IUTPC \\ cirohv@hotmail.com \\ Puerto Cabello, Venezuela \\ https://orcid.org/0000-0003-3933-262X
}

\section{Resumen}

La educación constituye un ámbito de dimensiones complejas, porque está impregnada de valores e implica toma de postura personal desde el conocimiento, frente a la situación curricular y ante los mismos alumnos. Asimismo, responde a normas establecidas como patrones sociales y culturales, convertidas en convencionalismos por la misma sociedad. Por ello la necesidad actual: definir cuál será el nuevo hombre propuesto en el esquema de relaciones del Estado, la sociedad y la educación, lo cual lleva a repensar el proceso de enseñar y aprender. Es ésta la pretensión del ensayo producto de vivencias investigativas en educación, orientado a redescubrir la complejidad de la realidad educativa, como vía expedita para introducir mejoras en el escenario de la escuela. De igual forma constituye una invitación al reencuentro investigador-investigado, entrelazados en una realidad, que le es común y que los desafía a que la conozcan y transformen. Siendo así, el panorama actual de investigación escolar, amerita la necesidad de relacionar metodologías en conjunción con las emergentes valoraciones individuales y colectivas presentes en la sociedad, es decir, hilvanar las concepciones: proceso educativo-vida social y cimiento filosófico-práctica-educativa.

Palabras clave: proceso de aprendizaje; estudiante; profesor; práctica pedagógica. 


\title{
The Teaching and Learning Process: Inquiry from the Educational Context
}

\begin{abstract}
Education is an area of complex dimensions, because it is impregnated with values and implies taking a personal stance from knowledge, facing the curricular situation and before the students themselves. Likewise, it responds to established norms as social and cultural patterns, converted into conventions by the same society. Therefore, the current need: to define what the new man proposed in the scheme of State relations, society and education will be, which leads to rethink the process of teaching and learning. This is the pretense of the essay product of investigative experiences in education, oriented to rediscover the complexity of the educational reality, as an expeditious way to introduce improvements in the school's scenario. In the same way, it constitutes an invitation to the researcher-researched reunion, intertwined in a reality that is common to them and that challenges them to know and transform them. Thus, the current panorama of school research merits the need to relate methodologies in conjunction with the emerging individual and collective valuations present in society, that is, basing conceptions: educational process-social life and philosophical foundationeducational-practice.
\end{abstract}

Keywords: learning processes; student; teacher; teaching practice.

Date Received: 24-09-2018

Date Acceptance: 11-02-2019 


\section{Introducción}

El hecho formal de enseñar y aprender se comprende como la actividad humana, consistente en un proceso sistemático de entregarse el denominado maestro, educador o profesor con vocación de servicio al prójimo, en procura de ocupar espacios afectivos y emocionales al lado de quien se pretende enseñar, educar u orientar. Esta es la manera clásica y auténtica de transformación humana, practicada en la antigua Grecia por el Maestro Sócrates. En esta perspectiva, enseñar dentro del sistema educativo, es a todas luces una tarea práctica de aprendizaje continuo y transformador, que va dirigido en direcciones recursivas entre participantes, aun con el uso actual de herramientas tecnológicas de información y comunicación.

De manera tal, el hombre vive en comunidades originando los pueblos que les pertenece, por efecto, los maestros también llamados docentes, por su dedicación a enseñar, son ciudadanos que se insertan y se vinculan asumiendo en diálogo sus posturas, críticas, y controversias. Esto constituye un entramado de interacciones afectivas entre educador-educando; se trata de un fenómeno simultáneo en el que interviene la poli-diversidad del ser humano.

Por tanto, el ser motivador, del deseo de aprender corresponde pues, a un humano capacitado, con disposición a lidiar en las complejas redes de acción educativa, por las cuales se definen año tras año los perfiles académicos y experienciales, de los que hoy son aprendices y luego ocuparán los espacios laborales de un país.

De tal manera, que los vínculos de relación humana entre alumnomaestro constituye eje vital; si la pretensión es lograr que los alumnos de hoy sean capaces de transformar realidad, entonces, necesario es la formación educativa que les brinde autonomía en sus propios actos. En tal caso, el desempeño de esta diada constructora de comportamiento humano, debe estar desprendida de imperativos personales y de presunta autoridad o poder 
sobre los alumnos. Lo ideal sería que la realidad ontológica que encierra el ser educativo, privilegie la buena voluntad que puedan ejercer los sujetos que forman y los que están en formación cultural e idiosincrática.

\section{Para Yuni (2009a):}

enseñar es establecer una relación, es construir una posición que no está situada en coordenadas predefinidas, fijas y definitivas sino una posición que sufre alteraciones y que busca e inventa respuestas. Esa relación se establece con los saberes, es una relación con el otro, y con lo que ello genera en el maestro (pág. 104).

En atención a lo descrito, para comprender el significado del proceso de enseñanza y aprendizaje, es conveniente metafóricamente hablando entrelazar el maestro, el discípulo y educación como si fueran tres eslabones de una misma cadena, luego, contemplarlos con una mirada epistemológica transcompleja, verlos cuando están juntos en plena acción, en el salón de clase; de esta manera, las reflexiones e interpretaciones subsiguientes estarían lo más cercanas a la realidad ontológica de tal espectáculo, y es que no pueden comprenderse e interpretarse los actos humanos del proceso educativo, vistos desde fuera del contexto en que se realizan, porque dejaría un espacio importante de relaciones valorativas integradas e interacciones humanas sin avizorar.

\section{Contexto educacional}

La intencionalidad del maestro en su desempeño pedagógico y contexto escolar, debe priorizar el lazo emocional y de valoraciones morales, en la búsqueda por asumir como profesional de la educación. Esto significa romper con la rutina de la práctica educativa, asociada al pensamiento simple y descriptivo que poco favorece el aprendizaje por la verdadera vida socialmoral.

Es evidente, que el sistema de enseñanza aprendizaje, en cualquiera 
de los niveles educativos es fundamentalmente una relación de comunicación humana, es una transmisión continua de mensajes escritos, hablados y no verbales entre maestro- alumno y entre alumnos. Una comunicación que puede ser auténtica y facilitar la formación humana de todos los actores del proceso educativo, o bien puede ser un maestro hablando sólo, dictando notas y los alumnos memorizando cosas, apostando a otro tipo de fenómeno incierto.

En relación con tales afirmaciones, se menciona a continuación algunas estructuras de relaciones que derivan del proceso mismo de la educación y que son por naturaleza inmanentes al del propio acto de formación práctica en el hombre, en lo fundamental:

- Si desde el contexto de aprendizaje, no se admiten los gustos e intereses personales, se estarán negando la identidad cultural, nacional y el derecho a pertenecer a un territorio.

- Evocar aspectos cognitivos previos y reconocer el acervo cultural a través contenidos, implica generar nuevos aprendizajes, valorar y articular experiencias.

- No instruir en determinados conocimientos, presuponiendo que serán comprendidos o que no serán necesarios, desatiende el derecho a la información y las valoraciones del otro.

- Si desde el trabajo educativo se conciben los hechos como un retículo social envolvente, se comprenderán los procesos de interrelaciones y ámbitos de interés para el colectivo.

Lo anteriormente planteado, es posible abordarlo desde la complejidad, referido a lo incierto de la vida, lo que sugiere la reflexión crítica y diversa para intervenir la realidad ontológica. Desde esta lógica, Morín (2003a), agrega que: "la gente está sumergida en lo que él llama la inteligencia ciega que no ve más allá de sus propios límites, dicha inteligencia destruye los conjuntos y las 
totalidades, aísla todos sus objetos de sus ambientes" (pág. 16).

A tal efecto, la situación actual del trabajo escolar y escenario institucional es compleja, no solamente por el avance en la comprensión de lo que significa educar, la importancia del diálogo y la participación de todos los alumnos en el proceso de aprendizaje; sino por el arrollador flujo de información y comunicación en todas las ramas del saber humano, más aun, pareciera que el debate académico educativo y formal, no es suficiente para comprender en la actualidad, la vasta dimensionalidad de eventos sociales, culturales, políticos, económicos entre otros, y que compromete directamente el significado de la expresión educación.

Por otra parte, el maestro durante las clases parece responder más a normas establecidas como patrones sociales y culturales, convertidos en convencionalismos por la misma sociedad, y como un miembro más de la cultura social, lo traduce en su desempeño habitual con el alumno. Conviene destacar aquí, a Nietzsche (1983a), cuando advierte: "Quien es radicalmente maestro no toma ninguna cosa en serio más que en relación a sus discípulos, ni siquiera a sí mismo" (pág. 91); esto significa que el desempeño didáctico y pedagógico, debe estar enmarcado y orientado hacia la pluralidad social que define el comportamiento humano, y no es otra, que la autoproducción de estímulos en relación con los sentimientos más profundos de amor en otredad. Cabe mencionar lo que dijo alguna vez Simón Bolívar citado por Romero (2008), refiriéndose a la educación: "como el objeto más noble que puede ocupar al hombre" (pág. 71); para ilustrar a sus semejantes. En consonancia con este parecer, Morín (1999), conceptualiza: "La educación debe favorecer la aptitud natural de la mente para hacer y resolver preguntas esenciales y correlativamente estimular el empleo total de la inteligencia general" (pág. 17).

A tales argumentos, cuando se debate el problema de la estimulación y rendimiento escolar, el análisis se orienta por lo general a los alumnos: sus necesidades, ansiedades, intereses, pero esa reflexión queda inacabada si el 
maestro no auto-explora su propio modo de laborar; comunicar y revisar qué objetivos se consiguen con facilidad y en cuales necesita mejorar.

Es por lo que la educación tiene en sí misma, sustento de moralidad y una ética que la fundamenta y aporta normas para regir la acción pedagógica y humana, entonces se trata de estimular al hombre a ser humano, para que proponga no solo el ser autentico, sino la trascendencia de sí mismo como naturaleza indispensable para que su vida sea rebosante de bienestar y merecedora de existencia misma.

En el aula de clase durante la interacción profesor-alumno, el hablar y el escuchar implica el estar juntos y además aceptarse, en presencia de una conversación, que constituye una especie de recursividad multidireccional entre los participantes, que intercambian voces y ademanes. En el campo educativo, si el maestro no presta atención al discurso que dirige a sus alumnos, sus consecuencias, pueden atentar contra la armonía escolar, Maturana (2004a), sostiene que:

las convicciones y certezas manifestadas a diario, pueden ser limitantes porque comprometen conductas inadecuadas. Las certezas encierran un peligro fundamental: esconden las distintas opciones del sentir, pensar y actuar. De hecho, catalogar a los alumnos de brutos o flojos para el estudio es una demostración de convicción errónea de la realidad del alumno. Estas certidumbres, son algo muy poderoso, enceguecen y hacen pensar cualquier reflexión ulterior como pérdida de tiempo, si ya se conoce el único resultado posible de cualquier esfuerzo de reflexión adicional (pág. 27).

Prima entender que es a través del diálogo sincero, que no se puede abordar la realidad del alumno, y que es conveniente preguntarse acerca de los criterios y conductas que utiliza el alumno para ser como es. Tanto el que pretende formar como el que aprende, son observadores de sus propios encuentros, de su propia realidad que construyen durante las conversaciones y demás interacciones. Si dentro de la institución escolar, el común 
denominador es el alumno, porque se encuentra en todas partes, entonces, es la razón de ser de la escuela organizada, donde se encuentre el maestro, tendrá que estar conectado con el alumno, de lo contrario, la escuela como institución educativa desaparece, ambos ocupan la dimensión humana de existir, inseparablemente unidos al mundo educativo que le rodea.

En este escenario, las experiencias de los maestros no están dadas independientes de ellos mismos, las apreciaciones que éste tenga de los alumnos no pueden estar separadas de las situaciones vividas con los mismos, ya que las actividades académicas son experiencias compartidas, no son independientes del maestro orientador, cuando éste se pregunta qué está haciendo en el salón de clase, está colocando su comportamiento y juicios dentro de los lazos afectivos que lo envuelven con los alumnos.

\section{Valoraciones pedagógicas}

Debatir el problema axiológico en educación exige elegir un sólido fundamento teórico considerando la dialéctica que impone los procesos educativos de la actualidad, éstos reclaman respuestas contundentes a la incertidumbre de los valores en dichos procesos. Se entiende que la ciencia positivista ha posicionado históricamente procesos empírico-analíticos y normas del debate hipotético deductivo en los sistemas educativos, es decir, las prácticas de esta ciencia positivista, han formado la idea en las ciencias humanas y en especial la educación de que lo que interesa para la ciencia y para la vida es el conocimiento puramente natural, objetivo y externo, sin que para ello haga falta la subjetividad de los actores.

En lo que al trabajo educativo se refiere, la conjunción entre lo subjetivo y lo objetivo deben ser verdades y valores éticos de promoción permanente, porque se trata de los mismos cultivadores de la sociedad, de las instituciones y de la ciencia. Se entiende que en el proceso de conocer, ocurren eventos mentales donde las personas procesan la información relativa que captan 
sensorialmente, luego la transforman en marcos de referencia, que constituyen finalmente un sistema de representación de la realidad cotidiana.

Para Frondizi (1986a): "El valor ético tiene una fuerza impositiva que obliga a reconocerlo aún contra los deseos, tendencias e intereses personales" (pág. 36); Se infiere entonces, que el predominio de las actitudes y posiciones individuales sobre el medio externo, no tiene razón de ser cuando se trata de juzgar honestamente el comportamiento del otro, esto quiere decir, que en el caso educativo, el que enseña y evalúa debe sobreponerse a realidades lineales y parcializadas, deformadoras de estimación moral y ética.

El autor parece no estar de acuerdo con que las actuaciones personales, propiamente subjetivas derivadas de algún estado psicológico o fisiológico, sean las que decidan los momentos en que se requiera de actitudes de respeto, honestas o de justicia cuando se comparten espacios sociales. Por encima de todo interés personal, advierte, el valor ético debe imponerse para evitar la deformación del mismo, lo dicho no le confiere privilegios a la parte objetiva, pues de lo que se trata, es de establecer un equilibrio entre las dos dimensiones de estas realidades.

La apreciación, esclarece el hecho de que los maestros podrían estar manifestando actitudes subjetivas que contradicen la realidad objetiva y la invulnerabilidad, de los valores educativos dispuestos en la normativa legal, no obstante, la enseñanza elemental no es en primera instancia internalizar contenidos por asignaturas, sino de aportar luces, conservando el balance entre lo subjetivo y lo objetivo, atendiendo formar para la vida del individuo humano.

Las actitudes entre maestro-alumno, tienden entonces, a constituir complejas redes de representación de la realidad en la que se mueven, se trata de posiciones personales particulares subjetivas que determinan juicios consensuados. Después de todo, estos sistemas de significados responden a complejos modos de vida que limitan la realidad objetiva del salón de clase, 
pero como ya lo dijo Frondizi (1986b): "de lo que se trata es de valorar honestamente el comportamiento del otro: del alumno" (pág. 36).

En este contexto los educadores tienen una gran responsabilidad, ya que deben trascender el ámbito exclusivamente escolar para situarse junto con los estudiantes en concordancia con el contexto social, esta labor amerita de un docente capaz de administrar un currículo complejo que le permita diseñar situaciones didácticas escolares y extraescolares, donde la comunicación debe ser una constante para formar estudiantes, que se inserten activamente de sus derechos y atribuciones, en la dinámica de sus entornos familiares y escolares, a decir de Maturana (1996a): "Los valores son distinciones de configuraciones relacionales en la convivencia, que obtienen su legitimidad desde la emoción del amor... que constituyen al otro en la convivencia, honestidad, cooperación, respeto, lealtad, generosidad, responsabilidad, justicia" (pág. 244).

Se evidencia, que la práctica educativa no es el producto de saberes eminentemente académicos, ella se encuentra bajo el influjo de una serie de creencias e intereses provenientes del contexto en que está inmerso el educador, de allí, que la misma está cargada de configuraciones mentales subjetivas. Desde esta óptica, Maturana (1996b): confiere a los valores un origen de la vida cotidiana y se fundan en el amor, "el respeto se da en la aceptación del otro, como un legítimo otro en la convivencia, y donde hay colaboración que se da sólo en el respeto mutuo, desaparecen la arrogancia y la obediencia" (pág. 244); cabe preguntarse aquí, ¿será que hay consideración a los cuestionamientos planteados por el alumnado?

Ello explica que las valoraciones Maturana (1996c): "se viven y se contagian en el vivir, la preocupación por las consecuencias que tienen las acciones de uno sobre otro adquiere sentido desde la legitimidad del otro como un ser con el cual se construye dichas valoraciones" (pág. 246). A tal sentido, en educación se comparte el encuentro académico-personal y se construye el 
ser ontológico universidad-comunidad en la que se cohabita compartiendo valoraciones. Otro interrogante que destacar, ¿será posible la coexistencia armoniosa en el encuentro alumno-profesor?

En palabras de Yuni (2009b): la "crisis de la educación" (pág. 108); alude a cuestiones de índole técnica, planes de estudio desactualizados, exceso de asignaturas, contenidos alejados de los intereses de los estudiantes, necesidad de actualización disciplinar y capacitación a los docentes, metodologías inapropiadas y muchas carencias adjudicadas a los estudiantes, aspectos que considerados de manera aislada y despojados del sentido contextual representan más de lo mismo.

Un modelo educativo promotor del derecho a la formación en valores de los jóvenes, insta a repensar el rol del maestro. Un profesorado democrático y pedagógicamente innovador, está obligado a revisar los modelos de interacción que rige en las aulas, se verá forzado a abandonar certezas en las funciones que debe desempeñar.

El maestro que demuestre siempre confianza en las capacidades de los alumnos, que sepa contagiarles optimismo y les eleve constantemente su autoestima, que inste a la participación colectiva horizontal, para ayudarles a ejercer como ciudadanos y ciudadanas dignos en el ambiente de la institución educativa, será un profesional consciente de la responsabilidad que implica el cargo que ejerce, como lo establece el Preámbulo de la norma Constitucional en la Constitución de la República Bolivariana de Venezuela (1999a), el pueblo de Venezuela con el fin supremo de refundarse se constituye en: "una sociedad democrática, participativa y protagónica" (pág. 4).

Habría que preguntarse hasta qué punto la conflictividad y la violencia escolar, la inmensa mayoría de las veces, no son el fruto de modelos autoritarios; en este orden, el maestro debe difundir la idea al alumnado de que es él, el más interesado en el diálogo y en prestarle atención a las opiniones de los alumnos. En efecto, existe la presunción de que los maestros 
se encargarán de mantener y transmitir ciertos valores en nombre de la sociedad en general, sigue considerándose a éste como guía y ejemplo moral, responsable del desarrollo de las capacidades mentales de los jóvenes, Pourtois (2004a), argumenta que valor: “...es todo lo que vale, todo lo que se puede amar o desear, todo lo que puede movilizarnos, todo lo que merece nuestra atención o que puede prevalecer sobre otra cosa. No hay educación sin valor" (pág. 168).

Por estas razones, el maestro preocupado por los valores educativos, del amor, solidaridad, responsabilidad y honestidad, entre otros, debe estar comprometido también con valorar en sentido racional el modo de vida estudiantil. Muchas veces se les exige a los alumnos que adopten determinada conducta en clase, mientras el docente es el primero en hacer todo lo contrario, de este modo, la moralidad del maestro viene a ser un tipo de consciencia, una sensibilidad por la humanidad del alumno; esto traduce autonomía y voluntad para comprender que hay interrelación humana entre los participantes del proceso educativo, es una especie de consciencia propia que emerge del alma del maestro en forma deliberada y libre, movido por la respuesta de bienestar que le causa el alumno.

En una clase programada, es posible que en principio, el maestro tenga que preconizar con estrategias de enseñanza y reglas básicas de atención; pero un aspecto de los objetivos orienta a que los alumnos conquisten por sí mismos la importancia de tal normativa, y es más previsible que lo hagan per se y puedan protagonizar en su instauración. Es obvio, en libertad los alumnos pueden plantear nuevas normas y, vivir experiencias en discusiones con distintos marcos de diálogo y debate conjunto, reflexionando sobre los motivos por los que algunas críticas parecen no llevar a ningún sitio y otras alcanzan un resultado que deja a todo el mundo la percepción de bienestar y validez moral. 


\section{Ser natural en educación}

El encuentro educativo entre maestro y alumno, involucra la personalidad fundida en el entramado de conductas y pareceres presentes en los protagonistas más cercanos maestro-alumno, e incide en el espacio de relaciones humanas mantenidas en el contexto académico y social. El desempeño educativo, es una actividad que se ubica dentro de un hecho social, supone un intercambio de preferencias, creencias e ideologías imponderables e inciertas.

Según Morín (2003b): "Estamos condenados al pensamiento incierto, a un pensamiento acribillado de agujeros, a un pensamiento que no tiene ningún pensamiento absoluto de certidumbre. Pero somos capaces de pensar en esas condiciones dramáticas" (pág. 101); en virtud de lo expuesto, lo educativo supone relación e interacción compleja de diálogo entre actores, exalta la intencionalidad natural de la especie humana como lo es, el vivir agrupado para accionar con los avatares del contexto. Lo descrito permite intuir las posibilidades de elegir lo cognoscible en el libre albedrío que subyace al interior del pensamiento humano.

Es necesario destacar en este párrafo, dos postulados que definen la complejidad, lo cual podría ayudar a pensar el complicado escenario educativo, el primero según Morín (2003c):

es el principio llamado dialógico, que habla del orden y desorden como dos enemigos: uno suprime al otro, pero al mismo tiempo, en ciertos casos colaboran y producen la organización y la complejidad. El principio dialógico, según la teoría, permite la dualidad en el seno de la unidad. Asocia dos términos a la vez complementarios y antagonistas (pág. 67).

Se observa que esta proposición invita al entendimiento entre las partes que constituyen un todo, en este caso, se trata del diálogo comprensivo e intencional que está inserto en el proceso educativo y busca en el hombre, 
valoraciones que trascienden lo puramente material e instrumental.

El segundo principio, Morín (2003d):

es el definido como un proceso recursivo en el cual los productos y los efectos son, al mismo tiempo, causas y productores. La idea recursiva, rompe con la noción lineal de causa/efecto, porque todo lo que es producido reentra sobre aquello que lo ha producido en un ciclo en sí mismo auto-constitutivo, auto-organizador y autoproductor (pág. 67).

Esta idea es válida en educación, las relaciones entre profesor-alumno son producidas por otras interacciones entre ellos, pero lo que se enseña en esas relaciones, retro actúa sobre profesores-alumnos.

Asimismo, Scheler (2003a), advierte sobre la gran confusión de valores por la que está viviendo el hombre en la actualidad: "Al cabo de unos diez mil años de historia, es nuestra época la primera en que el hombre se ha hecho plena, e integralmente problemático ya no sabe lo que es, pero sabe que no lo sabe" (pág. 10). Parece que, a comienzos de la segunda década del presente siglo por lo que implica la vida planetaria, deberíamos hablar de expresiones más abarcadoras cuando se pretende dilucidar el accionar humano referido a los valores. Al respecto, el vocablo valor designa actitudes, capacidades, personalidad o comportamiento, dicha expresión, sin la cual el discurso referido al comportamiento humano, no tiene razón de ser, parece quedar corta en la semántica del discurso académico y social de la actualidad. El proceso histórico de explosión demográfica y avance científico-tecnológico a nivel mundial, demanda desde los sentimientos y emociones, de nuevos debates, formas de expresión y posturas epistemológicas, de allí que, el significante del término en el ámbito educativo parece estar en evolución.

Este horizonte de florecientes cualidades y valores utilitarios de la emotividad cotidiana, es visto históricamente desde una dimensión espiritual por Scheler (2003b): "El sentir es un acto espiritual, autónomo e intencional, frente a todos los estados del sentimiento meramente empíricos" (pág. 149). 
La profundidad y abstracción teórica de los sentimientos humanos, constituye un aporte esclarecedor del confuso clima de valores manifestados en el acto educativo. Los afectos y las emociones se comunican verbalmente, pero sobre todo a través del lenguaje no verbal, de ahí la necesidad de ser plenamente conscientes del valor de estas interacciones en toda interacción con el alumno. Es el lenguaje verbal el que más se suele controlar en los procesos de interrelación, descuidando otras formas de comunicación, los gestos, las expresiones faciales, los tonos de voz, y las posturas corporales suelen transmitir con mayor sinceridad lo que se está pensando acerca de la persona con la que tiene lugar la interacción.

Para Maturana (2004b): "Sólo los seres humanos son capaces de tomar responsabilidades en el dominio relacional, porque existen en el lenguaje: tienen la capacidad de describir un determinado acto como responsable" (pág. 43); en efecto, el proceso educativo es una actividad fundamentalmente cultural y es a través del uso del lenguaje que se manifiestan las conductas valorativas que vehiculizan el accionar de alumnos y profesores.

Efectivamente, en el campo de la educación, existe un flujo de emociones entre los actores, que describen las conductas y modos de relacionarse, al respecto Maturana (2004c):

afirma que el amor es el dominio de aquellas conductas relacionales a través de las cuales otro surge como un otro legítimo en coexistencia con uno mismo bajo cualquier circunstancia. Todos los valores tienen que ver con el amor y son expresión de la armonía social, pues, lo social se funda en el amor (pág. 251).

Sin embargo, cuando el proceso educativo de entendimiento y comprensión presenta desacuerdos, frustraciones o decepciones, debe suceder según Maturana (1996d): "el respeto por la propia experiencia, desde la autonomía del pensamiento propio y desde la autonomía crítica y valorativa" (pág. 260). Desde esta óptica representacional, Nietzsche (1983b), 
complementa estas ideas, cuando refiere: "el amante del conocimiento debe escuchar sutil y diligentemente, debe tener sus oídos en todos aquellos lugares en que se hable..." (pág. 51); es tácito, comprender el rasgo biológico de compañerismo y solidaridad latente entre humanos, pero que sin embargo existe la frustración y decepción cuando se les somete a la indiferencia y la agresión.

De tal manera que el conocimiento y manejo de conceptos relacionados con el asunto de las emociones humanas en el campo educativo, es viable para comprender las actitudes personales de los actores, cuando desempeñan el trabajo de enseñar y aprender; la pertinencia de estos aspectos, radica en los planteamientos sobre el vivir de cada instante, en el conversar desde el espacio de relaciones conductuales y en la convivencia social.

En atención a este marco descriptivo, es pertinente incorporar el pensamiento pedagógico de Rogers (1972a), quien postula:

la persona es capaz de controlar su propio desarrollo, es un organismo vivo que posee instinto de desarrollo. No es el maestro quien debe dar algo al alumno, es el alumno quien debe descubrir por sí mismo lo que necesita (pág. 70).

De hecho, los conocimientos pueden hacerse de forma empírica y autoadquirida, según esta teoría, los alumnos como seres humanos poseen una capacidad natural para aprender: son curiosos, ávidos de conocer el mundo. Un aprendizaje válido tiene lugar cuando el alumno percibe su objeto como si tuviese relación con sus proyectos personales, cada alumno sólo aprende adecuadamente lo que considera que puede conservar su propio yo el maestro debe, pues, ayudar al estudiante a encontrar y tratar problemas que sean significativos para él.

El aprendizaje consiste en confrontar al estudiante con los problemas prácticos, los problemas sociales, morales y las dificultades personales, el auténtico aprendizaje se facilita cuando el estudiante escoge por sí sólo 
orientación, cuando contribuye a escoger por sí solo medios de aprendizaje, cuando formula personalmente dificultades, cuando el mismo decide el desarrollo del aprendizaje y cuando enfrenta directamente las consecuencias de sus decisiones.

Un aprendizaje autodeterminado que inmiscuye a la persona en su totalidad, con sus sentimientos, pasiones y emociones, es interiorizado con más facilidad, porque es un aprender de él mismo y para sí mismo, Rogers (1972b), sustenta estos planteamientos, cuando postula: "para mí, el ingrediente más importante que el facilitador brinda al grupo es la confianza" (pág. 70); para dar al alumno libertad de aprender, el docente facilitador, establecerá un clima de recreación y esparcimiento para generar confianza y respeto, depositará su mayor confianza en la tendencia de los estudiantes de aceptarse ellos mismos, su función consiste, pues en desarrollar una relación personal con éstos en un clima que favorezca desarrollo de sus potencialidades.

En relación con lo dicho, Pourtois (2004b), plantea que: "para ser facilitador, el docente deberá aceptarse a sí mismo, conocer sus propios límites, en una palabra, ser auténtico, a sea, será el mismo, sin fachadas y sin máscaras, condición primaria de toda relación verdadera" (pág. 218); el maestro auténtico será adecuado, es decir, no interpondrá ninguna separación entre su yo ideal y su yo real; su afectividad estará libre de todo temor y podrá establecer entonces una relación directa y sin deformación.

El orientador o pedagogo, comprenderá, pues, los sentimientos que manifiesta el estudiante y aceptará a éste, tal como es, optando por una actitud de positiva consideración condicional, es decir, le reconocerá como persona con valores. Cualquiera que sea su situación, comportamiento y sentimientos; la aceptación incondicional es primeramente la exigencia de respetar al alumno, en cuanto tiene el derecho a ser diferente de mí. 


\section{En resumen}

El predio educativo no puede cristalizar en una línea resignada de presuntas valoraciones que distancian el ideal de ilustrar; el educador abnegado no está para restringir la lógica de su razón; perentorio es optar por la postura de transformación, enseñar con el ejemplo a construir críticamente la realidad, usar el sentido común, junto al sano juicio en la formación de personalidad.

Cada profesor es el resultado de una familia, de un entorno social, de unos amigos, de una personalidad y también conforma un equipo de profesores que le da sentido y configuración a una institución educativa. Vivir en sociedad significa convivencia, significa que las actuaciones afectan a los demás y viceversa.

De lo que se trata es de hacer feliz al alumno, en función del deber universal de la interrelación en el conversar amistoso, para el convivir social. Este es el cómo hacerlo, la forma natural que tiene el ser humano de relación con la vida y con el mismo, es una herramienta ontológica, de convivencia consensuada que enseña, se comparte con alumnos y humaniza, les reporta: respeto entre ellos mismos y un espacio para la imaginación, el descubrimiento y satisfacción personal y colectiva.

Beneficio epistemológico se puede obtener de dicha herramienta, por cuanto trasciende la unidad lógica de la teoría educativa actual, además, interroga la narrativa académica y el discurso interesado, dado que señala de modo racional, el horizonte en el que, lo cognoscitivo del cómo hacerlo, sustenta bases filosóficas y científicas de la educación. Asimismo, fortalece en materia pedagógica, los principios plasmados en los artículos 02 y 03 de la Constitución de la República Bolivariana de Venezuela (1999b):

Venezuela se constituye en un Estado democrático y social de Derecho y de Justicia, que propugna como valores superiores de su ordenamiento jurídico y de su actuación, la vida, la libertad, la justicia, la igualdad, la solidaridad, la democracia, la 
responsabilidad social y en general, la preeminencia de los derechos humanos, la ética y el pluralismo político. El Estado tiene como fines esenciales la defensa y el desarrollo de la persona y el respeto a su dignidad, el ejercicio democrático de la voluntad popular, la construcción de una sociedad justa y amante de la paz, la promoción de la prosperidad y bienestar del pueblo (pág. 1).

El texto Constitucional hace expresivo la voluntad política orientada al fomento de la educación, finalmente, es un exhorto a los educadores de buena voluntad, a no entumecerse y expongan con criterios prácticos, a continua revisión y autoanálisis su actuación educativa, mientras se ofrezcan soluciones metodológicas prácticas en el encuentro personal, la teoría pedagógica tenderá a ser menos abstracta en sus principios básicos. En virtud de esto, la búsqueda es por integrar los elementos de organización que prescriben el cómo hacer emerger bienestar personal, un ser de esta naturaleza manifiesta el sendero por la transformación de la ciencia de la educación.

\section{Referencias}

Constitución de la República Bolivariana de Venezuela (1999a,b). Gaceta

Oficial Extraordinaria $\mathbf{N}^{\circ} \mathbf{3 6 . 8 6 0}$ de fecha $\mathbf{3 0}$ de diciembre. Caracas, Venezuela: Asamblea Nacional Constituyente.

Frondizi, R. (1986a,b). ¿Qué son los valores? Tercera edición. México: Fondo de Cultura Económica.

Maturana, H. (1996a,b,c,d). El sentido de lo humano. Chile: Ediciones Dolmen S.A.

Maturana, H. (2004a,b,c). Del ser al hacer. Chile: Comunicaciones Noreste. Morín, E. (1999). Los siete saberes necesarios para la educación del futuro. Barcelona, España: Ediciones Paidós.

Morín, E. (2003a,b,c,d). Introducción al pensamiento complejo. Sexta 
reimpresión. España: Gedisa Editorial.

Nietzsche, F. (1983a,b). Más allá del bien y del mal. España: Ediciones Orbis.

Pourtois, J. (2004a,b). La Educación postmoderna. España: Editorial Popular.

Rogers, C. (1972a,b). Libertad para aprender. París, Francia: Dunod Editions.

Romero, V. (2008). Diccionario del pensamiento bolivariano. Ideas frases y expresiones del Libertador. Caracas, Venezuela: Editorial Panapo.

Scheler, M. (2003a,b). Gramática de los sentimientos. Lo emocional como fundamento de la ética. España: Crítica.

Yuni, J. (2009a,b). La formación docente. Complejidad y ausencias. Primera edición. Argentina: Editorial Encuentro. 


\section{Ciro Hernández Valderrama \\ e-mail: cirohv@hotmail.com}

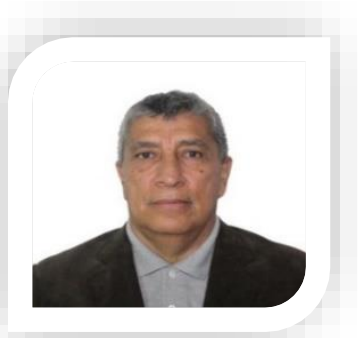

Nacido en el Estado Trujillo, Venezuela. Licenciado en educación, mención: Orientación egresado de Universidad de Carabobo; Maestría en Educación Básica (Universidad Nacional Experimental Rómulo Gallegos); Doctor en Ciencias de la Educación (Universidad Fermín Toro); Postdoctorado en Estudios Libres (UFT); Cuya agenda constituye un proceso sistematizado de investigación, producción, análisis y comunicación de conocimientos. Así mismo, la epistemología como una reflexión filosófica en torno al estado del arte científico, que pretende dar cuenta de los modos de pensar y conocer los estilos de pensamiento, teorías y prácticas en campos disciplinares específicos. Profesor Asociado, coordinador del área Formación Humanística, adscrito a Departamentos de Mecánica Térmica y Automotriz en la Universidad Politécnica de Puerto Cabello, Venezuela. Diseñador y motivador en proyectos de orientación con valores de convivencia institucional, docente-alumno y socio-comunitaria. Ponente en congresos académicos. Participante con artículos en revistas científicas. Dictaminador en revistas científicas: ARJE, Ciencias de la Educación, EDUCARE UPEL IPB, Investigaciones Interactivas COBAIND, SCIENTIARUM, EDUCARE UNA. Jurado en trabajos de ascenso: UNIPAP, IUTPC. Tutor de tesis UC. Investigador socioeducativo, en la dimensión ético-moral del hombre. Certificado en el Programa de Estímulo a la Innovación e Investigación. PEll convocatoria 2015-2016, Investigador A-1, adscrito al Observatorio Nacional de Ciencia Tecnología e Innovación (ONCTI).

El contenido de este manuscrito se difunde bajo una Licencia de Creative Commons ReconocimientoNoComercial-Compartirlgual 4.0 Internacional 